\title{
$\kappa$-Opioid Agonists Directly Inhibit Midbrain Dopaminergic Neurons
}

\author{
Elyssa B. Margolis, ${ }^{1}$ Gregory 0. Hjelmstad, ${ }^{2}$ Antonello Bonci, ${ }^{2}$ and Howard L. Fields ${ }^{1,2}$ \\ ${ }^{1}$ Joint University of California San Francisco/University of California, Berkeley Bioengineering Graduate Group, San Francisco, California 94143-0775, and \\ ${ }^{2}$ Department of Neurology, Wheeler Center for the Neurobiology of Addiction, Ernest Gallo Clinic and Research Center, University of California, San \\ Francisco, California 94143-0114
}

\begin{abstract}
Dopaminergic neurons of the ventral tegmental area (VTA) play a critical role in motivation and reinforcement of goal-directed behaviors. Furthermore, excitation of these neurons has been implicated in the addictive process initiated by drugs such as morphine that act at the $\mu$-opioid receptor (MOR). In contrast, $\kappa$-opioid receptor (KOR) activation in the VTA produces behavioral actions opposite to those elicited by MOR activation. The mechanism underlying this functional opposition, however, is poorly understood. VTA neurons have been categorized previously as principal, secondary, or tertiary on the basis of electrophysiological and pharmacological characteristics. In the present study using whole-cell patch-clamp recordings, we demonstrate that a selective KOR agonist (U69593, $1 \mu \mathrm{M})$ directly inhibits a subset of principal and tertiary but not secondary neurons in the VTA. This KOR-mediated inhibition occurs via the activation of a G-protein-coupled inwardly rectifying potassium channel and is blocked by the selective KOR antagonist nor-Binaltorphimine (100 $\mathrm{nM})$. Significantly, regardless of cell class, KOR-mediated inhibition was found only in tyrosine hydroxylase-immunoreactive and thus dopaminergic neurons. In addition, we found a subset of principal neurons that exhibited both disinhibition by a selective MOR agonist ([D-Ala ${ }^{2}, \mathrm{~N}-\mathrm{Me}-\mathrm{Phe}^{4}$, Gly-ol ${ }^{5}$-enkephalin) $(3 \mu \mathrm{M})$ and direct inhibition by KOR agonists. These results provide a cellular mechanism for the opposing behavioral effects of KOR and MOR agonists and shed light on how KORs might regulate the motivational effects of both natural rewards and addictive drugs.
\end{abstract}

Key words: ventral tegmental area; midbrain; dopamine; $\kappa$-opioid; $\mu$-opioid; U69593; DAMG0; postsynaptic; in vitro

\section{Introduction}

$\kappa$ - and $\mu$-Opioid receptor (KOR and MOR) agonists have opposing actions in a number of systems in the brain, including those mediating reward, motivation, and pain modulation (Pan, 1998). The ventral tegmental area (VTA) is a critical site for opioid effects on motivation. Intra-VTA injections of MOR agonists elicit conditioned place preference (CPP): rats spend more time in a context paired with MOR agonist administration than in a saline-paired environment (Phillips and LePiane, 1980; BalsKubik et al., 1993; Nader and van der Kooy, 1997). Conversely, intra-VTA microinjections of KOR agonists produce conditioned place aversion (CPA) (Bals-Kubik et al., 1993).

There is evidence that an increase in dopamine (DA) release from VTA neurons contributes to the positive motivational actions of MOR agonists. VTA dopaminergic neurons project densely to the nucleus accumbens (NAc), and dialysis studies show that VTA microinjections of the MOR selective agonist $\left[\mathrm{D}-\mathrm{Ala}^{2}, \mathrm{~N}\right.$-Me-Phe ${ }^{4}, \mathrm{Gly}_{-} \mathrm{ol}^{5}$ ]-Enkephalin (DAMGO) increase DA release in the NAc (Latimer et al., 1987; Leone et al., 1991;

Received July 7, 2003; revised Sept. 4, 2003; accepted Sept. 10, 2003.

This work was supported by funds provided by the State of California for medical research on alcohol and substance abuse through the University of California, San Francisco, and by National Institute on Drug Abuse Grant DA01949. We thank Kelly Pollak for her technical assistance and Woody Hopf for helpful comments.

Correspondence should be addressed to Elyssa B. Margolis, Ernest Gallo Clinic and Research Center, 5858 Horton Street, Suite 200, Emeryville, CA 94608. E-mail: emargoli@socrates.berkeley.edu.

Copyright $\odot 2003$ Society for Neuroscience $\quad$ 0270-6474/03/239981-06\$15.00/0
Spanagel et al., 1992; Devine et al., 1993). Furthermore, DA action in the NAc is critical for MOR agonist-elicited behavioral effects. In opiate-exposed rats, CPP produced by intra-VTA morphine is blocked by systemic dopamine antagonists (Nader and van der Kooy, 1997), and MOR agonist-induced CPP is blocked by 6-OHDA destruction of NAc DA terminals (Shippenberg et al., 1993). The requirement for DA in expression of morphine CPP supports the hypothesis that enhanced firing of VTA dopaminergic neurons contributes to the positive motivational actions of MOR agonists.

Do KOR agonists contribute to aversion by decreasing the firing rate of VTA dopaminergic neurons? KORs are functionally expressed in the VTA (Speciale et al., 1993; Arvidsson et al., 1995; Mansour et al., 1996), and dynorphin, an endogenous opioid peptide with high selectivity for the KOR, is present in projections to the VTA from several structures strongly implicated in motivation and reinforcement, including the NAc, amygdala, and hypothalamus (Fallon et al., 1985; Meredith, 1999). Although KOR agonists inhibit DA release from cultured VTA neurons (Ronken et al., 1993; Dalman and O'Malley, 1999), this decrease in DA release does not distinguish an effect at the cell body from one on the terminals of the cultured neuron. Because microinjections of KOR agonists directly into the NAc in vivo produce place aversions and inhibit DA release (Bals-Kubik et al., 1993), several investigators have proposed that the aversive action of systemically administered KOR agonists is mediated pri- 
marily by their direct inhibition of DA release from the terminals of VTA neurons in the NAc (Xi and Stein, 2002). However, this hypothesis does not explain how microinjection of a KOR agonist directly into the VTA produces aversion, nor does it address the function of dynorphinergic projections to the VTA. A necessary first step toward resolving these questions is to determine the direct actions of KOR agonists on the different classes of neurons in the VTA, including the subset that release DA. Here we report that KOR agonists directly inhibit a subset of DA-containing neurons in the VTA.

\section{Materials and Methods}

Slice preparation and electrophysiology. Male Sprague Dawley rats, 20-36 d old, were anesthetized with isoflurane, and the brains were removed. Horizontal brain slices (150-250 $\mu \mathrm{m}$ thick) containing the VTA were prepared using a Vibratome (Leica Instruments, Nussloch, Germany). Slices were submerged in Ringer's solution containing (in mM): $119 \mathrm{NaCl}, 2.5 \mathrm{KCl}$, $1.3 \mathrm{MgSO}_{4}, 1.0 \mathrm{NaH}_{2} \mathrm{PO}_{4}, 2.5 \mathrm{CaCl}_{2}, 26.2$ $\mathrm{NaHCO}_{3}$, and 11 glucose saturated with $95 \%$ $\mathrm{O}_{2}-5 \% \mathrm{CO}_{2}$ and allowed to recover at $35^{\circ} \mathrm{C}$ for at least $1 \mathrm{hr}$.

Individual slices were visualized under a Zeiss Axioskop with differential interference contrast optics and infrared illumination. Whole-cell patch-clamp recordings were made at $31^{\circ} \mathrm{C}$ using $2.5-4 \mathrm{M} \Omega$ pipettes containing (in $\mathrm{mm}$ ): 123 K-gluconate, 10 HEPES, 0.2 EGTA, 8 $\mathrm{NaCl}, 2 \mathrm{MgATP}$, and $0.3 \mathrm{Na}_{3} \mathrm{GTP}, \mathrm{pH} 7.2$, osmolarity adjusted to 275$)$. Biocytin (0.1\%) was added to the internal solution for experiments in which cells were filled for later tyrosine hydroxylase $(\mathrm{TH})$ staining.

Recordings were made using an Axopatch 1-D (Axon Instruments, Union City, CA), filtered at $2 \mathrm{kHz}$, and collected at $5 \mathrm{kHz}$ using IGOR Pro (Wavemetrics, Lake Oswego, OR). Liquid junction potentials were not corrected during current- or voltage-clamp recordings. $I_{\mathrm{h}}$ currents were recorded by voltage clamping cells and stepping from -60 to $-40,-50$, $-70,-80,-90,-100,-110$, and $-120 \mathrm{mV}$. Cells were recorded in current-clamp mode $(I=0)$ for experiments measuring spontaneous firing rates. In some experiments, $500 \mathrm{~nm}$ tetrodotoxin (TTX) was added to the bath solution to block neural activity after a stable $10 \mathrm{~min}$ baseline was observed, and U69593 and DAMGO were subsequently added to this TTX solution. Current-voltage data were collected in voltage clamp by stepping from a holding potential of -60 to $-40 \mathrm{mV}$ and ramping down to $-140 \mathrm{mV}$ over a 2 sec interval. Dose-response data were collected with repeated applications of increasing doses of U69593 in each cell and are reported as the percentage of the inhibition produced by a maximal dose of $5 \mu \mathrm{M}$ in each responding cell.

For data analysis, instantaneous firing rate was computed as the inverse of the interspike interval after each action potential. Results are presented as means \pm SEM where appropriate. For each cell, the statistical significance of drug effects was tested with the paired Student's $t$ test, comparing the last $4 \mathrm{~min}$ of baseline with the last $4 \mathrm{~min}$ of drug application.

All drugs were applied by bath perfusion. Stock solutions were made and diluted in Ringer's immediately before application. U69593 stock was diluted in $50 \% \mathrm{EtOH}$ to a concentration of $1 \mathrm{~mm}$; norBinaltorphimine (nor-BNI) (10 mM) and DAMGO (1 mM) were diluted in $\mathrm{H}_{2} \mathrm{O}$; TTX (5 mM) was diluted in DMSO. Agonists, antagonists, ATP, and GTP were obtained from Sigma (St. Louis, MO) or Tocris (Ballwin, MO).

Immunohistochemistry. Immediately after recording, slices were fixed for $2 \mathrm{hr}$ in $4 \%$ formaldehyde. Slices were preblocked for $2 \mathrm{hr}$ in PBS with $0.2 \%$ Triton X-100, $0.2 \%$ BSA. and 5\% normal goat serum. Rabbit anti-TH antibody (1:100) was then added, and the slices were agitated at $4^{\circ} \mathrm{C}$ for $48 \mathrm{hr}$. Finally, slices were agitated with FITC anti-rabbit secondary antibody (1:100) and Texas Red avidin $(11.0 \mu \mathrm{l} / \mathrm{ml})$ at $4^{\circ} \mathrm{C}$ overnight. Cells were visualized with a Zeiss LSM 510 META microscope.

Biocytin, BSA, and normal goat serum were obtained from Sigma . Texas Red avidin was obtained from Jackson ImmunoResearch (West Grove, PA), and rabbit anti-TH antibody and FITC anti-rabbit secondary antibody were obtained from Chemicon (Temecula, CA).

\section{Results}

In these experiments, we studied postsynaptic KOR-mediated actions in vitro using current-clamp recordings of neurons in horizontal rat brain slices of the VTA. We classified neurons according to their electrophysiological and pharmacological properties. Principal cells exhibit an $I_{\mathrm{h}}$ and long action potentials (Fig. $1 A)$. Secondary cells lack an $I_{\mathrm{h}}$, have shorter action potentials (Fig. $1 B$ ), and are generally considered to be GABAergic interneurons in both the VTA (Johnson and North, 1992a) and the neighboring substantia nigra zona compacta (Grace and Onn, 1989; Lacey et al., 1989). Secondary cells are also inhibited by MOR agonists (Fig. 1B) (Lacey et al., 1989; Johnson and North, $1992 \mathrm{a}, \mathrm{b})$. Although there is a consensus that most VTA principal 
Table 1. Principal and tertiary VTA neurons have similar electrophysiological properties but respond differently to $\mu$-and $\kappa$-opioids

\begin{tabular}{|c|c|c|c|c|c|c|c|}
\hline Cell type & $\begin{array}{l}\text { Mean firing rate } \\
(\mathrm{Hz})\end{array}$ & $I_{\mathrm{h}}$ size $(\mathrm{pA})$ & $\begin{array}{l}\text { Inhibited by } \\
\text { U69593 only }\end{array}$ & $\begin{array}{l}\text { Inhibited by } \\
\text { DAMGO only }\end{array}$ & $\begin{array}{l}\text { Inhibited by U69593 } \\
\text { and DAMGO }\end{array}$ & $\begin{array}{l}\text { Disinhibited by } \\
\text { DAMGO only }^{a}\end{array}$ & $\begin{array}{l}\text { Inhibited by U } 69593 \text { and } \\
\text { disinhibited by DAMGO }\end{array}$ \\
\hline Principal $(n=47)$ & $1.3 \pm 0.2$ & $-240 \pm 30$ & 12 & $X$ & $X$ & 10 & 12 \\
\hline Secondary $(n=9)$ & $3 \pm 1$ & $1 \pm 2$ & $x$ & 9 & 0 & $x$ & $X$ \\
\hline Tertiary $(n=25)$ & $1.2 \pm 0.2$ & $-280 \pm 40$ & $X$ & 9 & 16 & $X$ & $X$ \\
\hline
\end{tabular}

Summary of current-clamp recordings in both spontaneously firing and quiescent VTA neurons. Each drug was bath applied independently for 5 min. Note: By definition, all secondary and tertiary cells were inhibited by DAMG0. Neuronal properties that are not compatible with our cell type definitions are denoted by " $X$. ." (See Results.)

${ }^{a}$ Effect criterion is paired $t$ test of baseline to the last 4 min of drug application within each cell. $p<0.05$.
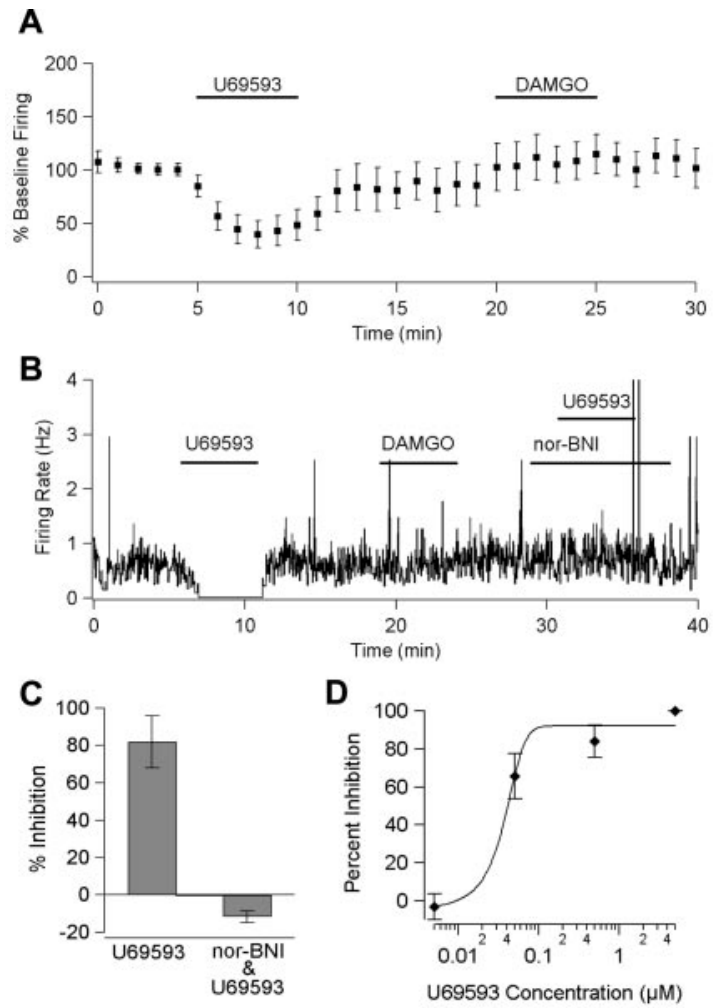

Figure 2. $\kappa$-Opioids in the VTA are inhibitory through activation of KOR. $A$, The firing rate of spontaneously active principal neurons $(n=26)$ is inhibited by bath application of U69593 (1 $\mu \mathrm{M})$ but not DAMGO $(3 \mu \mathrm{M})$. B, In a single cell, the U69593-evoked (5 $\mu \mathrm{m})$ inhibition is completely blocked during reapplication of U69593 $(5 \mu \mathrm{M})$ in the presence of the KOR-selective antagonist nor-BNI (100 nM). C, Nor-BNI (100 nm) blocked the U69593 (5 $\mu \mathrm{m})$ inhibition in all tested cells ( $n=4$; error bars indicate SEM). D, Dose-response curve for U69593 inhibition ( $n=4$ for each point; error bars indicate SEM).

neurons are dopaminergic, Cameron et al. (1997) and Jones and Kauer (1999) have shown that a significant proportion of $I_{\mathrm{h}^{-}}$ expressing VTA neurons are not immunoreactive for the enzyme TH. Furthermore, Cameron et al. (1997) identified a third class of neurons in the VTA that they call "tertiary" cells. Tertiary cells have soma morphology and action potential shape (Fig. 1C) very similar to those of principal cells, but tertiary neurons are inhibited by MOR agonists and serotonin and fewer than one-third of tertiary cells are $\mathrm{TH}(+)$ (Cameron et al., 1997). We classified $I_{\mathrm{h}}$-expressing neurons as principal neurons if MOR agonists either had no effect or disinhibited the cells (Fig. $1 A$ ) and as tertiary if MOR agonists were inhibitory (Fig. 1C). We found no differences between tertiary and principal neurons for resting membrane potential, mean firing rate, or size of the $I_{\mathrm{h}}$ current (Table 1).

Principal neurons had an initial membrane potential of $-44.4 \pm 0.8 \mathrm{mV}$, and most (26 of 47) exhibited spontaneous activity. The KOR agonist U69593 inhibited 16 of 26 spontaneously active principal neurons $(1 \mu \mathrm{M})$ (Fig. $2 A)$. About one-third

\section{A Principal}

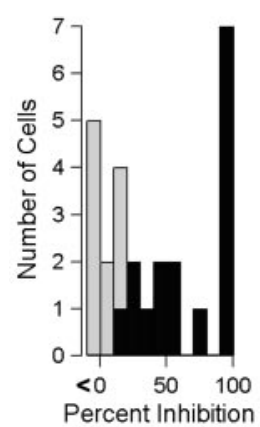

B Secondary

C Tertiary
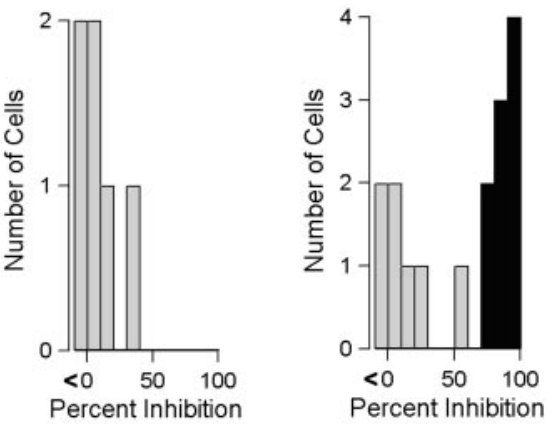

Figure 3. Spontaneous activity of principal and tertiary neurons is inhibited by $U 69593$. Distributions of inhibition by $U 69593(1 \mu \mathrm{M})$ in all spontaneously active principal $(A)$, secondary $(B)$, and tertiary $(C)$ neurons. A significant change in the firing rate attributable to drug compared with baseline within each cell is indicated by a darkened bar. $p<0.05$.

(8 of 21) of the principal neurons that were not firing spontaneously were hyperpolarized by U69593 (3.0 $\pm 0.8 \mathrm{mV})$. Consistent with the finding of Johnson and North (1992b) that MOR agonists disinhibit principal cells in the VTA in vitro, we observed an increase in spontaneous firing rate and depolarization in a subset (22 of 47) of principal neurons after application of DAMGO (3 $\mu \mathrm{M})$ (Table 1). This disinhibition has been attributed to a MOR agonist-induced inhibition of spontaneously active GABAergic interneurons that allows principal neurons to fire more (Johnson and North, 1992b). Thus, our data suggest that at least some critical intra-VTA circuitry is preserved in these slices.

We found no evidence for desensitization of the action of U69593 on the timescale of these experiments. A KOR-mediated inhibition of similar magnitude was evoked repeatedly in a single cell after ample washout time had elapsed (two applications of 5 min each per cell; $n=3$ ). Furthermore, cells maintained stable inhibitions during extended applications of U69593 ( $t>20 \mathrm{~min}$; $n=6)$. In KOR agonist-sensitive cells, the KOR selective antagonist nor-BNI (100 nM) completely blocked the effect of a subsequent application of U69593 ( $5 \mu \mathrm{M} ; n=4)$, confirming that the observed inhibition depends on the activation of KORs (Fig. $2 B, C)$. The U69593-mediated inhibition was dose dependent, and dose-response experiments in KOR agonist-responsive neurons yielded an $\mathrm{EC}_{50}$ of $42 \mathrm{~nm}$ (Fig. $2 \mathrm{D}$ ).

Secondary neurons, which lack an $I_{\mathrm{h}}$ current and hyperpolarize in response to MOR agonists, could also be distinguished by their smaller size and relatively brief action potential. Secondary neurons were unaffected by U69593 (spontaneously active cells: mean change $0.2 \pm 0.3 \mathrm{~Hz}, n=6$; quiescent cells: mean change $0.8 \pm 2.1 \mathrm{mV}, n=3$ ) (Fig. $3 B$, Table 1 ), confirming previous findings (Lacey et al., 1989; Johnson and North, 1992a). On the other hand, a significant proportion of tertiary cells, which have an $I_{\mathrm{h}}$ and hyperpolarize in response to MOR agonists, were responsive to KOR activation. Nine of 16 spontaneously firing ter- 
tiary neurons were inhibited by U69593 (Fig. 3C), and 7 of 9 nonfiring tertiary neurons were hyperpolarized by U69593 $(2.9 \pm 0.9 \mathrm{mV})$ (Table 1$)$.

The observation that DAMGO induces disinhibition in principal neurons indicates that some local circuitry is intact in the slice. Thus, to confirm that the inhibitory action that we observed was caused by a direct effect of the KOR agonist on the postsynaptic membrane of the recorded cell, it was necessary to measure the U69593 inhibition while blocking neural activity. In the presence of TTX (500 nM), 4 of 10 neurons with an $I_{\mathrm{h}}$ (5 primary, 4 tertiary, 1 not classified) hyperpolarized when $\mathrm{U} 69593$ was added to the bath solution $(5.0 \pm 0.9 \mathrm{mV})$ (Fig. $4 A$ ). Additionally, the TTX itself had a depolarizing effect on the baseline membrane potential $(5.3 \pm 0.4 \mathrm{mV}$ after $5 \mathrm{~min}$ of bath application; $p=0.01)$. This TTX-elicited depolarization implies that in this VTA slice preparation there is spontaneous activity of neurons that releases a hyperpolarizing neurotransmitter such as GABA or dopamine that acts on primary and tertiary neurons.

To test whether KOR activation inhibits these neurons by enhancing the G-protein-coupled inwardly rectifying potassium (GIRK) channel, we applied a voltage ramp (step from -60 to $-40 \mathrm{mV}$, ramp down to $-140 \mathrm{mV}$ ) before and during exposure to U69593. The current-voltage plot for the U69593-sensitive component of this voltage ramp showed a reversal potential of $-93 \mathrm{mV}$, close to the calculated $\mathrm{K}^{+}$reversal potential $(n=7)$ (Fig. $4 B$ ) and had a diminished slope for positive current, suggesting that the KOR is associated with a GIRK channel.

Because some principal and most tertiary neurons are nondopaminergic (Cameron et al., 1997) and a significant proportion of both cell types was not affected by KOR agonists, immunohistochemical identification of dopaminergic neurons is an essential step for interpreting the KOR agonist effect on VTA neurons. To determine whether the principal and tertiary cells inhibited by U69593 are indeed dopaminergic, biocytin was added to the internal pipette solution, and after recording, the brain slices were fixed and stained for TH. Seventeen biocytinfilled VTA neurons were electrophysiologically defined, processed for TH reactivity, and recovered. Nine were principal neurons, seven were tertiary, and one was secondary (Table 2). All six recovered cells that were inhibited by $\mathrm{U} 69593$ were $\mathrm{TH}(+)$ and had an $I_{\mathrm{h}}$. Three of these were principal neurons (Fig. 5A). Six other principal neurons were unaffected by U69593, and one of these was $\mathrm{TH}(-)$ (Fig. $5 B$ ). Three of seven recovered tertiary neurons were both $\mathrm{KOR}$ agonist responsive and $\mathrm{TH}(+)$. The four KOR agonist-insensitive tertiary neurons were $\mathrm{TH}(-)$. Thus, KOR agonist-responsive neurons are a subset of dopaminergic neurons in the VTA, and most, if not all, KOR agonist-responsive neurons are $\mathrm{TH}(+)(p<0.05$; Fisher exact test), regardless of whether they are principal or tertiary cells. Importantly, our results demonstrate that there is a subset of VTA dopaminergic neurons (tertiary cells) that are inhibited by both MOR and KOR agonists.

\section{Discussion}

Our work shows that KOR-selective agonists directly inhibit dopaminergic neurons in the VTA. Twenty-five percent of the principal neurons reported in this study exhibited both a KOR agonistinduced inhibition and a MOR agonistinduced disinhibition. This observation confirms and extends the work of Johnson and North (1992b), who originally described MOR agonist-mediated inhibition of GABAergic inputs to VTA principal cells. Although the percentage of neurons exhibiting MOR agonist disinhibition is relatively small, it likely represents a significant underestimate of the proportion of cells that actually exhibit these opposing actions in vivo. It is probable that some intra-VTA circuitry is lost during the slicing procedure, and this loss decreases the number of cells showing a disinhibition with DAMGO. Additionally, in the Johnson and North study (1992b), the bath application of $\mathrm{K}^{+}$was required to increase GABA release sufficiently to demonstrate disinhibition, whereas we observed the disinhibition without a manipulation to increase GABA release.

The opposing MOR and KOR agonist actions on principal cells suggest a mechanism for the opposing behavioral effects on place preference when these opioids are microinjected into the VTA (Bals-Kubik et al., 1993). Our results are also consistent with in vivo studies suggesting that changes in dopaminergic neuron firing encode the value of cue-associated outcomes during goaldirected behavior such that increases are positively reinforcing and decreases lead to extinction of the behavior (Schultz, 1998). Thus, VTA injections of positively reinforcing MOR agonists indirectly excite principal neurons through disinhibition, whereas aversive KOR agonists, at the same site, directly inhibit principal neurons.

Our immunohistochemical results specifically and selectively localize the postsynaptic KOR-mediated inhibition to dopaminergic neurons. Although direct KOR agonist inhibition did not occur in every VTA dopaminergic neuron, it was observed only in such neurons. This is of particular significance because previously suggested cellular markers, such as action potential shape and duration, firing rate, presence of $I_{\mathrm{h}}$, and D2 agonist inhibition, do not in fact distinguish dopaminergic from nondopaminergic VTA neurons (Grace and Onn, 1989; Johnson and North, 1992a; Cameron et al., 1997; Jones and Kauer, 1999). Our results reinforce the point that there are no established electrophysiological or pharmacological properties that specifically delineate dopaminergic neurons from non-dopaminergic neurons in the VTA. Clearly, no current classifications of VTA neurons do justice to the heterogeneity of cell responses that are observed. For example, in the current study, we found $I_{\mathrm{h}}$ neurons that fell into all four possible categories: MOR agonist-inhibited, KOR agonist-inhibited, inhibited by both MOR and KOR agonists, and inhibited by neither. Additionally, the approach taken by Cameron et al. (1997) and used in this study, i.e., delineating a subgroup of neurons (tertiary cells) expressing an $I_{\mathrm{h}}$ and being directly inhibited by MOR agonists, is a demonstrably inadequate
A

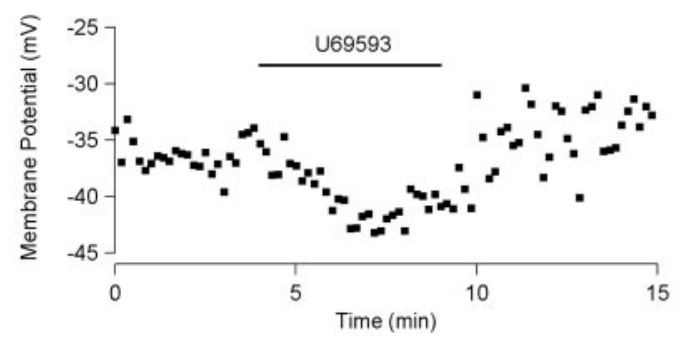

B

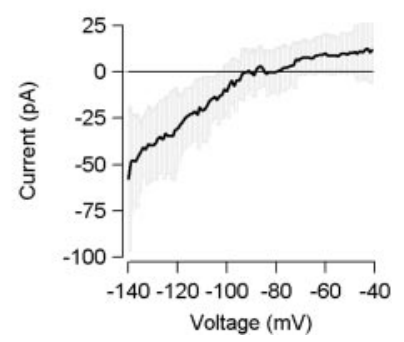

Figure 4. KOR agonist inhibition of VTA neurons is postsynaptic and mediated by GIRK activation. $A$, In the presence of TTX ( 500 nM) to block neural activity, U69593 causes hyperpolarization in an example cell. B, In recordings made without TTX, the difference between control and U69593 (1 $\mu \mathrm{m})$ current-voltage curves during a voltage ramp test shows inward rectification and a reversal potential of $-93 \mathrm{mV}$ ( $n=7 ; 95 \%$ confidence interval indicated in gray). 
Table 2. Dopamine-containing neurons are inhibited by $\kappa$-and $\boldsymbol{\mu}$-opioids

\begin{tabular}{lllll}
\hline & $\begin{array}{l}\kappa \text { inhibition } \\
\text { only }^{a}\end{array}$ & $\begin{array}{l}\kappa \text { and } \mu \\
\text { inhibition }^{a}\end{array}$ & $\begin{array}{l}\mu \text { inhibition } \\
\text { only }^{a}\end{array}$ & $\begin{array}{l}\text { Neither } \kappa \text { nor } \\
\mu^{a}\end{array}$ \\
\hline $\mathrm{TH}(+)(n=11)$ & 3 & 3 & 0 & 5 \\
$\mathrm{TH}(-)(n=6)$ & 0 & 0 & $5^{b}$ & 1 \\
\hline
\end{tabular}

Summary of current-clamp recordings in both spontaneously firing and quiescent VTA neurons loaded with biocytin during recordings and stained for TH afterwards. Each drug was bath applied independently for $5 \mathrm{~min}$.

${ }^{a}$ Effect criterion is paired $t$ test of baseline to the last 4 min of drug application within each cell. $p<0.05$.

${ }^{b}$ Data include four tertiary cells and one secondary cell.

indicator for non-dopaminergic VTA neurons. This issue is highlighted by the fact that half of the $\mathrm{TH}(+)$ neurons that were inhibited by a KOR agonist were also inhibited by a MOR agonist. Clearly, a more reliable and meaningful characterization of cell types in the VTA is needed. One intriguing possibility is that consistent pharmacological differences will coincide with different projection targets and sources of afferent input. Such information will be critical for gaining a more robust understanding of the contribution of dopaminergic VTA neurons to motivation and reward.

Previous studies have demonstrated a decrease in dopamine release in VTA cell cultures when KOR agonists are applied (Ronken et al., 1993; Dalman and O'Malley, 1999); however, these cell culture experiments leave open to question the cell types and proportion of cells affected. Furthermore, KOR agonists bath applied to cultured neurons could act at either the cell body or the dopaminergic terminals, or both. In our whole-cell slice recordings, we show that KOR agonists directly activate receptors on the soma-dendritic region of a subset of dopaminergic neurons, which in turn inhibit these neurons through the activation of a GIRK channel.

Although we found a clear inhibition of dopaminergic neurons by KOR agonists, Spanagel et al. (1992) and Devine et al. (1993) did not observe a change in the DA concentration detected by microdialysis in the NAc after microinjection of KOR agonists into the VTA. One possible confound in these dialysis experiments is that the measurements were made in anesthetized animals, and it is likely that the firing patterns of the VTA neurons were different from those in awake, behaving rats given KOR agonists in the conditioned place preference paradigm. If VTA dopaminergic neurons are not spontaneously active in anesthetized rats, it would not be possible to demonstrate inhibition of firing by soma-dendritic application of KOR agonists. On the other hand, microinjections of KOR agonists in the VTA have been reported to decrease extracellular dopamine in the NAc after it has been increased by systemic administration of haloperidol (Leyton et al., 1992). Furthermore, KOR agonists delivered by microdialysis into the substantia nigra of awake rats significantly decrease dopamine release in the neostriatum (You et al., 1999). Behaviorally, 6-OHDA lesions of the NAc block place aversion elicited by systemic KOR agonists (Shippenberg et al., 1993). These studies indicate that modulating the dopaminergic signal to the NAc with KOR agonists in the VTA is not only possible but may be necessary for the expression of behavioral effects of KOR agonists in the VTA.

In conclusion, we demonstrate that KOR agonists directly inhibit a subset of dopaminergic VTA neurons. At least some of these neurons are also disinhibited by MOR agonists. The direct KOR-mediated inhibition of principal neurons that are also disinhibited by MOR agonists is a motif that has been found previously in the CNS (Pan, 1998), although other arrangements have been reported (Ackley et al., 2001; Marinelli et al., 2002). Of the three VTA cell types studied here, it is only dopaminergic principal neurons that are both inhibited by KOR agonists and disinhibited by MOR agonists. Thus, principal cell opioid responses provide the simplest explanation for the opposing behavioral effects elicited by MOR and KOR agonists injected into the VTA. Secondary cells are unaffected by KOR agonists, and tertiary cells

A
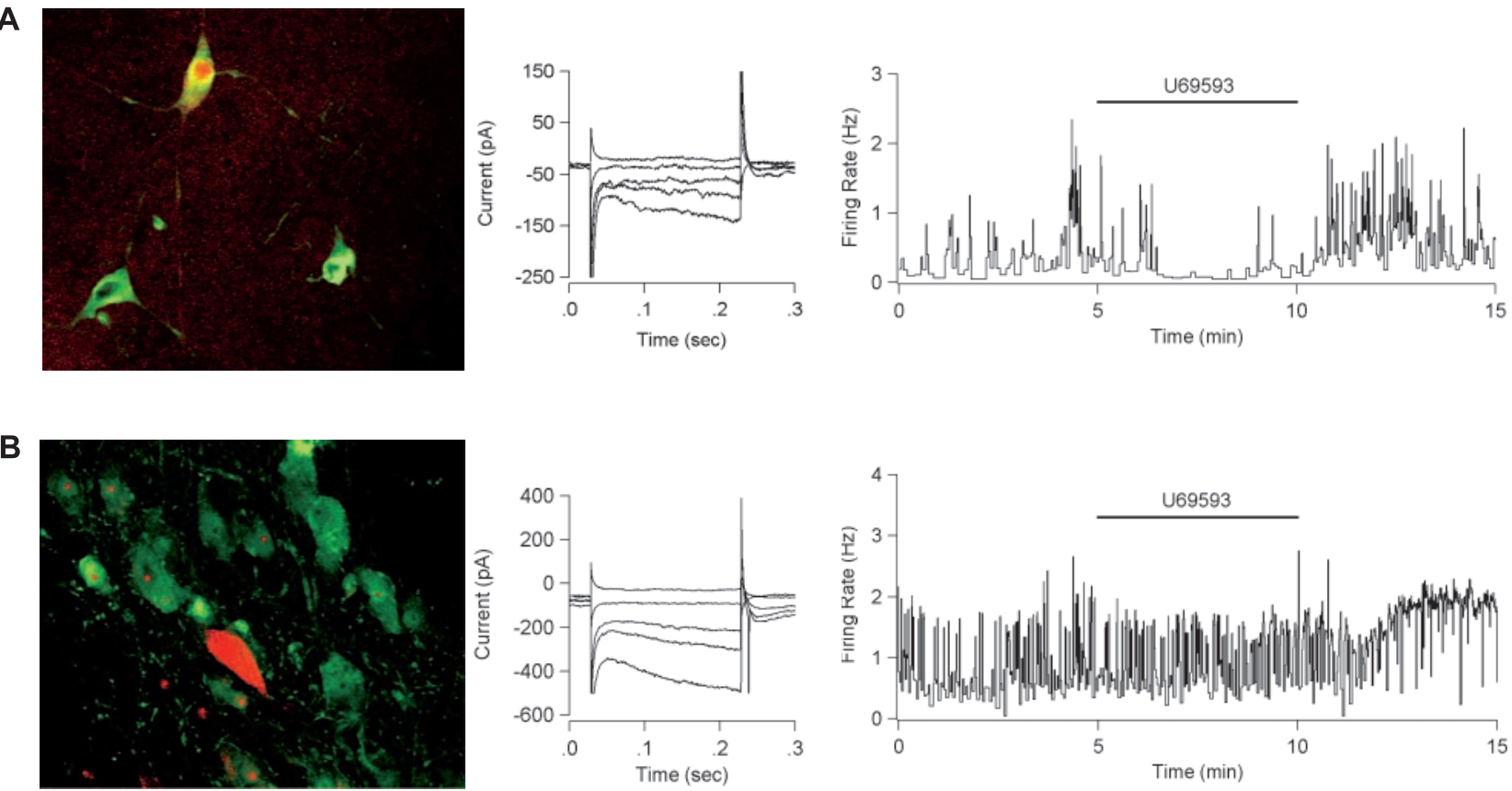

Figure 5. KOR activation inhibits dopaminergic neurons. $A$, A principal neuron filled with biocytin (red) during electrophysiological recording is costained with TH antibody (green) (left). This neuron exhibited an $I_{\mathrm{h}}$ current when tested with $200 \mathrm{msec}$ voltage steps from -60 to $-50,-70,-90,-100$, and $-120 \mathrm{mV}$ (center). The KOR agonist U69593 (1 $\mu \mathrm{m}$ ) inhibited spontaneous activity of this neuron held in current clamp at $I=0$ (right). $B, A$ principal neuron filled with biocytin (red) is not costained with $\mathrm{TH}$ antibody (green). This neuron also exhibited an $I_{\mathrm{h}}$ current. U69593 $(1 \mu \mathrm{M})$ had no effect on the firing rate of this neuron. 
are inhibited by both MOR and KOR agonists, and thus neither is a likely candidate for providing preference-related information. The opposing behavioral effects of MOR and KOR agonists acting in the VTA can be explained by the segregation of MORs and KORs onto distinct but interconnected subpopulations of neurons that produce outputs of opposite sign. Our data extend a growing body of evidence that endogenous KOR agonists play an important general role in modulating circuits implicated in motivation and reinforcement (Shippenberg et al., 2001). By directly inhibiting dopaminergic VTA neurons, KOR agonists can powerfully control the motivational effects of both natural and drug rewards.

\section{References}

Ackley MA, Hurley RW, Virnich DE, Hammond DL (2001) A cellular mechanism for the antinociceptive effect of a kappa opioid receptor agonist. Pain 91:377-388.

Arvidsson U, Riedl M, Chakrabarti S, Vulchanova L, Lee JH, Nakano AH, Lin X, Loh HH, Law PY, Wessendorf MW, et al (1995) The kappa-opioid receptor is primarily postsynaptic: combined immunohistochemical localization of the receptor and endogenous opioids. Proc Natl Acad Sci USA 92:5062-5066.

Bals-Kubik R, Ableitner A, Herz A, Shippenberg TS (1993) Neuroanatomical sites mediating the motivational effects of opioids as mapped by the conditioned place preference paradigm in rats. J Pharmacol Exp Ther 264:489-495.

Cameron DL, Wessendorf MW, Williams JT (1997) A subset of ventral tegmental area neurons is inhibited by dopamine, 5-hydroxytryptamine and opioids. Neuroscience 77:155-166.

Dalman FC, O'Malley KL (1999) $\kappa$-Opioid tolerance and dependence in cultures of dopaminergic midbrain neurons. J Neurosci 19:5750-5757.

Devine DP, Leone P, Wise RA (1993) Mesolimbic dopamine neurotransmission is increased by administration of mu-opioid receptor antagonists. Eur J Pharmacol 243:55-64.

Fallon JH, Leslie FM, Cone RI (1985) Dynorphin-containing pathways in the substantia nigra and ventral tegmentum: a double labeling study using combined immunofluorescence and retrograde tracing. Neuropeptides 5:457-460

Grace AA, Onn SP (1989) Morphology and electrophysiological properties of immunocytochemically identified rat dopamine neurons recorded in vitro. J Neurosci 9:3463-3481.

Johnson SW, North RA (1992a) Two types of neurone in the rat ventral tegmental area and their synaptic inputs. J Physiol (Lond) 450:455-468.

Johnson SW, North RA (1992b) Opioids excite dopamine neurons by hyperpolarization of local interneurons. J Neurosci 12:483-488.

Jones S, Kauer JA (1999) Amphetamine depresses excitatory synaptic transmission via serotonin receptors in the ventral tegmental area. J Neurosci 19:9780-9787.

Lacey MG, Mercuri NB, North RA (1989) Two cell types in rat substantia nigra zona compacta distinguished by membrane properties and the actions of dopamine and opioids. J Neurosci 9:1233-1241.

Latimer LG, Duffy P, Kalivas PW (1987) Mu opioid receptor involvement in enkephalin activation of dopamine neurons in the ventral tegmental area. J Pharmacol Exp Ther 241:328-337.

Leone P, Pocock D, Wise RA (1991) Morphine-dopamine interaction: ventral tegmental morphine increases nucleus accumbens dopamine release. Pharmacol Biochem Behav 39:469-472.

Leyton M, Rajabi H, Stewart J (1992) U-50,488H into A10 reduces haloperidol-induced elevations of accumbens dopamine. NeuroReport 3:1127-1130.

Mansour A, Burke S, Pavlic RJ, Akil H, Watson SJ (1996) Immunohistochemical localization of the cloned kappa 1 receptor in the rat CNS and pituitary. Neuroscience 71:671-690.

Marinelli S, Vaughan CW, Schnell SA, Wessendorf MW, Christie MJ (2002) Rostral ventromedial medulla neurons that project to the spinal cord express multiple opioid receptor phenotypes. J Neurosci 22:10847-10855.

Meredith GE (1999) The synaptic framework for chemical signaling in nucleus accumbens. Ann NY Acad Sci 877:140-156.

Nader K, van der Kooy D (1997) Deprivation state switches the neurobiological substrates mediating opiate reward in the ventral tegmental area. J Neurosci 17:383-390.

Pan ZZ (1998) mu-Opposing actions of the kappa-opioid receptor. Trends Pharmacol Sci 19:94-98.

Phillips AG, LePiane FG (1980) Reinforcing effects of morphine microinjection into the ventral tegmental area. Pharmacol Biochem Behav 12:965-968.

Ronken E, Van Muiswinkel FL, Mulder AH, Schoffelmeer AN (1993) Opioid receptor-mediated inhibition of evoked catecholamine release from cultured neurons of rat ventral mesencephalon and locus coeruleus. Eur J Pharmacol 230:349-355.

Schultz W (1998) Predictive reward signal of dopamine neurons. J Neurophysiol 80:1-27.

Shippenberg TS, Bals-Kubik R, Herz A (1993) Examination of the neurochemical substrates mediating the motivational effects of opioids: role of the mesolimbic dopamine system and D-1 vs. D-2 dopamine receptors. J Pharmacol Exp Ther 265:53-59.

Shippenberg TS, Chefer VI, Zapata A, Heidbreder CA (2001) Modulation of the behavioral and neurochemical effects of psychostimulants by kappaopioid receptor systems. Ann NY Acad Sci 937:50-73.

Spanagel R, Herz A, Shippenberg TS (1992) Opposing tonically active endogenous opioid systems modulate the mesolimbic dopaminergic pathway. Proc Natl Acad Sci USA 89:2046-2050.

Speciale SG, Manaye KF, Sadeq M, German DC (1993) Opioid receptors in midbrain dopaminergic regions of the rat. II. Kappa and delta receptor autoradiography. J Neural Transm Gen Sect 91:53-66.

Xi ZX, Stein EA (2002) GABAergic mechanisms of opiate reinforcement. Alcohol Alcohol 37:485-494.

You ZB, Herrera-Marschitz M, Terenius L (1999) Modulation of neurotransmitter release in the basal ganglia of the rat brain by dynorphin peptides. J Pharmacol Exp Ther 290:1307-1315. 